\begin{tabular}{|c|c|}
\hline European Association for the & $\begin{array}{c}\text { Euternational Conference on Renewable Energies and Power Quality } \\
\text { and Power Quality (EA4EPQ) }\end{array}$ \\
(ICREPQ'12)
\end{tabular}

\title{
Demand Charge Under Nonsinusoidal Conditions
}

\author{
E. C. Sousa ${ }^{1}$, S. F. de Paula Silva ${ }^{1}$, A. W. F. V. Silveira ${ }^{1}$, L. C. Gomes ${ }^{1}$, A. Fleury $^{2}$ \\ ${ }^{1} \mathrm{UFU}-\mathrm{FEELT}$ \\ ${ }^{2}$ PUC-GO and UEG \\ Av. João Naves de Ávila - Santa Mônica, 2160, Uberlândia, Minas Gerais (Brazil) \\ e-mail: educosta.sousa@gmail.com, sergio@eletrica.ufu.br, gutofleury@gmail.com, lcgomes2005@gmail.com
}

\begin{abstract}
This paper aims to present a new point of view about the demand (active power) measured at the Point of Common Coupling (PCC) between the utility and the consumer when harmonic distortions are involved. The active power from distorted voltage and distorted current has harmonic components besides the fundamental component. Depending on the origin of the harmonic distortions, the active power due to this sum can result in higher or lower values in comparison to the fundamental component value. Such difference results in a higher or lower energy and demand billing and consequently, higher costs for the consumer or losses for the electric utility. Besides the financial issue, the one in disadvantage deals with the harmful effects of the harmonics generated by the other. Using theoretical analysis and computational simulations, the influence of the distortions from the electric utility or from the consumer are evaluated and compared.
\end{abstract}

\section{Key words}

harmonic distortions, demand charge, power quality, active power, harmonic direction.

\section{Introduction}

Among the definitions for electric power when dealing with non-sinusoidal waves, the active power does not generate discussions and is widely accepted by the electrical engineering society. Despite this apparent unanimity, this paper aims to present a new point of view of the active power measurement and, consequently, of energy measurement, for billing purposes.

Following the power electronic raise and its wide usage in electric installations in industry, commerce and residences, harmonic distortions have become familiar for professionals in this area and also for consumers.

In this way, the voltage waveform and, especially, the current waveform are not perfectly sinusoidal. Thus, the resulting electric power presents discrepancies in comparison to those formulations founded in classical electric circuit books.

Since the beginning of the last century, researchers have been seeking for appropriate measurement theories, formulations and procedures for this reality. Despite these efforts, there is no consensus on this issue yet. Among the different kinds of electric power, the reactive power corresponds to the most questioned component when resulted from distorted voltage and current. The active power is consolidated and corresponds to the average value of the instantaneous power waveform.

Although, the instantaneous power is influenced by the harmonic distortions and the average value of its wave may present higher or lower values than those from the voltage and current fundamental component (50 or 60 $\mathrm{Hz}$ ) only. Such difference is strongly related to the electrical system configuration before and after the measurement point. Thus, if the harmonic distortions came from the electric utility or from the consumer, the measured active power on the PCC would present different values and could lead to a higher or lower billing, depending on the electrical characteristics of the utility and the consumer.

According to this, harmonic distortions injected from the consumer may lead to a lower active power measurement than the fundamental one, and though, contribute to a reduction on the utility billing, even if the utility is not responsible for the distortions. On the other hand, distortions from the utility may lead to a higher active power measurement increasing the consumer's consumption and demand.

It is important to make clear that the precision of commercial meters and also the share of responsibility for distortions in the electric system are not in this paper's scope.

In this context, the objective of this paper is to contribute with a characterization of a fair active power measurement procedure without harm for both involved parts.

\section{Active Power Calculation}

The influence of the voltage and current distortions on the electric system is a widely studied subject. However, 
the decomposition of the instantaneous power in nonsinusoidal conditions is not as simple as it is in sinusoidal conditions. Consequently, a great number of proposals for the decomposition of electrical power have been presented over the years [1]. As a consequence, a lot of comparative studies for the different components of the electric power have been made by researches.

The bases of a distorted power are the voltage and current generated/caused by nonlinear loads. The voltage and current in time and frequency domain are expressed by:

$$
\begin{gathered}
\cdot \sin \left(h \cdot 2 \pi f t-\alpha_{h}\right) \\
V_{r m s}{ }^{2}=V_{0}{ }^{2}+\sum_{h=1} V_{h}{ }^{2} \\
i(t)=I_{0}+\sqrt{2} \cdot \sum_{h \in N^{+}} I_{h} \cdot \sin \left(h \cdot 2 \pi f t-\beta_{h}\right) \\
I_{r m s}{ }^{2}=I_{0}{ }^{2}+\sum_{h=1} I_{h}{ }^{2}
\end{gathered}
$$$$
v(t)=V_{0}+\sqrt{2} \cdot \sum_{h \in N^{+}} V_{h}
$$

Where $\mathrm{N}^{+}$is the set of positive integer numbers, $h$ is the harmonic order, $f$ is the system's fundamental frequency, $V_{0}$ and $I_{0}$ are continuous component's values and $V_{h}$ and $I_{h}$ are the RMS values of voltage and current respectively. The angular displacement of voltage and current are represented by $\alpha_{h}$ and $\beta_{h}$ respectively, and $t$ is the time.

In the same way as in sinusoidal conditions, the instantaneous electric power can be calculated by the voltage and current product, both instantaneous:

$$
p(t)=v(t) \times i(t)
$$

The Apparent Power $(\boldsymbol{S})$ is defined as:

$$
S=V_{r m s} \cdot I_{r m s}
$$

The above definitions are universally accepted and adopted by power decomposition researchers.

Budeanu, in 1927, was the first researcher to understand the fact that the apparent power has more than two components in nonsinusoidal conditions [2]. In 1932, Fryze proposed a simple model that would cause a great impact on the concepts of power [3], unlike Budeanu, Fryze uses time domain techniques. Based on the Fryze and Buchholz's work, Depenbrock presented, in 1962, the theory that himself called as the FBD ("Fryze-BuchholzDepenbrock") Method, which ponders the power conditioning on power decomposition [4]. The Czarnecki's approach, presented in 1984, offers an improvement of Fryze's model, in other words, provides more information about the loads and the kinds of compensator needed to improve the load's power factor [5].
The Institute of Electrical and Electronics Engineers (IEEE) group of studies for non-sinusoidal situations has published, in 2000, the IEEE Std. 1459-2000: Trial-Use Standard Definitions for the Measurement of Electric Power Quantities Under Sinusoidal, Non-sinusoidal, Balanced, or Unbalanced Conditions [6]. This standard was revised and replaced by the IEEE Std. 1459-2010, with same title [7]. With this document, the IEEE tries to standardize the studies on power decomposition in nonsinusoidal conditions.

Despite the fact that there is no consensus about decomposition methods for electric power in nonsinusoidal conditions, active power is well-defined. This paper is based on the definitions and formulations specified in the IEEE Std. 1459-2010.

The Active Power (7) is defined as the average value of the instantaneous power and can be decomposed in fundamental $\left(\boldsymbol{P}_{\mathbf{1}}\right)$ and harmonic $\left(\boldsymbol{P}_{\boldsymbol{H}}\right)$ parts:

$$
P=\frac{1}{k T} \int_{\tau}^{\tau+k T} p d t=P_{1}+P_{H}
$$

Where, $k$ is a positive integer number, $T$ is the instantaneous power wave's period and $\tau$ is the measurement starting time.

The Fundamental Active Power is:

$$
P_{1}=V_{1} I_{1} \cos \theta_{1}
$$

And the Harmonic Active Power:

$$
P_{H}=V_{0} I_{0}+\sum_{h \neq 1} V_{h} I_{h} \cos \theta_{h}=P-P_{1}
$$

\section{Measurement and Regulation}

The existing electric energy meters are divided in two groups: electromechanical ones, which work on the electromagnetic induction principle, and the electronic ones, that uses integrated circuits. Both are designed to work in purely sinusoidal conditions because standards and regulations do not include non-sinusoidal waveforms. So in the presence of harmonics, the measurement results depend on the specific project of each meter [8].

Some developed works [9-13] show that both electromechanical and electronic meters are affected by voltage and current distortions. Thus, the electric energy meters designed to work on linear systems may affect the trade between the utility and the consumers.

It is very important to adopt an appropriate methodology for consumer billing/measurement in the presence of harmonics and so to define the technical specifications that meters should follow when used with nonsinusoidal waveforms. Such definitions must consider the tolerable limits for distortions in the system. 
Analyzing the current standards and resolutions, it is clear that there is no definition to the energy measurement involving nonsinusoidal waveforms. Consequently, the values shown by meters depend solely on the technic implemented by their manufacturers. Those technics are valid for sinusoidal circuits but not for nonsinusoidal circuits [14].

Therefore, adopted electrical meters used for energy billing may present discrepancies on the active power values. In general, some meters make measurement only for the active power from voltage and current's fundamental values, while others calculate the average value of the instantaneous power considering possible voltage and current waveform distortions.

In the same way, the relationship between the electric utility and the consumer is harmed since the harmonic distortions are a phenomena widely founded in the electric system.

\section{Analysis}

The electrical energy billing takes into account the measurement of the active power that flows through the PCC. In the analysis presented here, for didactic purposes, a fictitious line with zero impedance is introduced between the load and the source to better characterize the parts involved in the calculation process.

First of all, in this case the consumer consists only of linear loads and all the harmonic content at the PCC is responsibility of the utility. This situation is shown in Fig. 1.

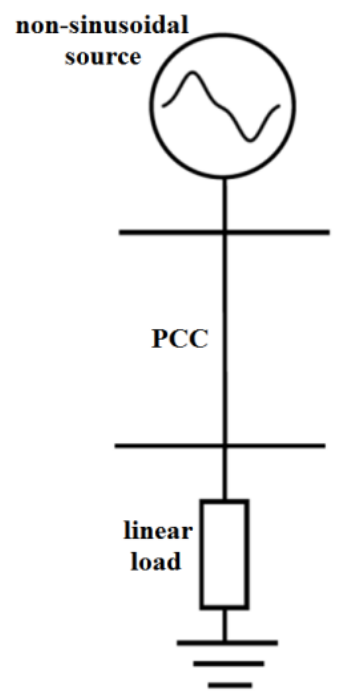

Fig. 1. Distorted source supplying a linear load.

The distorted voltage source is represented by a Norton equivalent circuit. Thus, the electric utility is modeled by a harmonic current source $\left(I_{H}\right)$ parallel to an equivalent impedance. It is important to remember that both the consumer's and the utility's equivalent impedance was represented by a resistance. This choice was based on the active power analysis, object of this work.
Fig. 2 shows the active power in the system, and illustrates that the power flows only from the electric utility to the consumer.

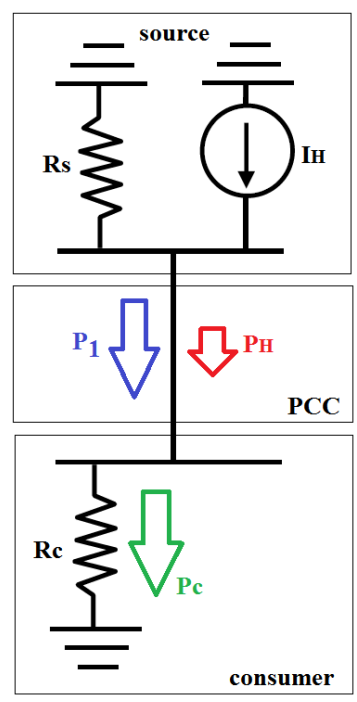

Fig. 2. Active Power Flow.

At the PCC, the active power consists of the Fundamental Active Power $\left(P_{1}\right)$ and the Harmonic Active Power $\left(P_{H}\right)$. The Consumer's Equivalent Resistance is determined by the expected/designed operation conditions, in other words, only by the fundamental parts (10).

$$
R_{c}=\frac{\left(V_{1}\right)^{2}}{P_{1}}
$$

The Active Power Absorbed by the Consumer $\left(P_{c}\right)$ is expressed by:

$P_{c}=R_{c} \cdot\left(I_{r m s}\right)^{2}=R_{c} \cdot\left(\frac{V_{r m s}}{R_{c}}\right)^{2} \Rightarrow P_{c}=\frac{\left(V_{r m s}\right)^{2}}{R_{c}}$

Substituting (10) in (11):

$$
P_{c}=\frac{\left(V_{r m s}\right)^{2}}{\left(\frac{V_{1}^{2}}{P_{1}}\right)}=\frac{\left(V_{r m s}\right)^{2}}{\left(V_{1}\right)^{2}} \cdot P_{1} \Rightarrow P_{c}=P_{1} \cdot\left(\frac{V_{r m s}}{V_{1}}\right)^{2}
$$

This way, despite of the fact that the consumer does not have any nonlinear load, an active power greater than the fundamental will be maintained. Therefore, in cases where the harmonic distortions are utility's responsibility and the consumer is harmed by the harmonic current circulation through its electrical system (higher Joule losses), the demand and active energy measurement for billing purposes may be greater than that required by sinusoidal conditions. This depends on the type of meter used by the consumer.

The second analyzed case studies a situation in which the consumer has nonlinear loads and the utility provides a purely sinusoidal voltage. In this case, the consumer is responsible for the whole harmonic content at the PCC. This case is shown in Fig. 3. 


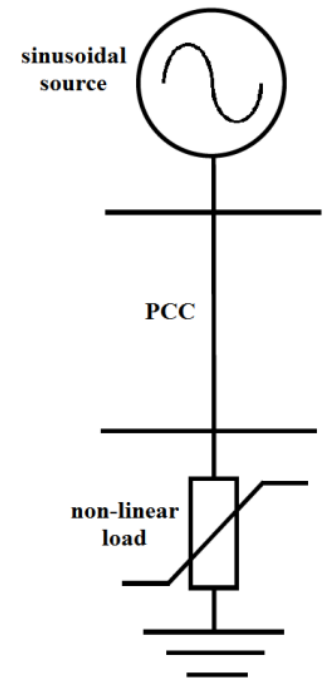

Fig. 3. Sinusoidal source with nonlinear load.

The flow of active power in the system, in the case shown in Fig.3 can be analyzed with Fig. 4.

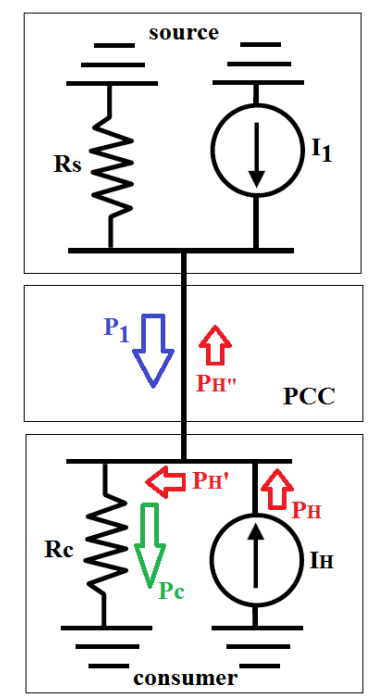

Fig. 4. Active Power Flow, fundamental and harmonic.

As illustrated in Fig 4, the active power flowing through the PCC consists of the fundamental component and also a portion from the harmonic components. In this case, as the direction of the Harmonic Active Power $\left(P_{H}{ }^{\prime \prime}\right)$ can be of opposite direction to the Fundamental Active Power $\left(P_{1}\right)$, there will be a reduction in the value of the active power measurement. Thus, the utility will be harmed because its system will get disturbed with the presence of harmonic distortion and also because the consumer's nonlinear loads contribute to an electric energy billing reduction.

\section{Computational Assessment}

This section discusses computer simulations that are prepared in order to illustrate the impact of harmonic power flow on total active power measured at the PCC.

The evaluation process is supported by a computer program that employs simulation techniques based on the frequency domain [15]. In this tool, a hypothetical electrical arrangement was modeled and parameterized and consists, essentially, by a supplying network defined by its short-circuit impedance and a consumption characterized by an equivalent load with resistive, capacitive and inductive parts, and also by nonlinear components.

Fig. 5 shows the arrangement and the corresponding parameters.

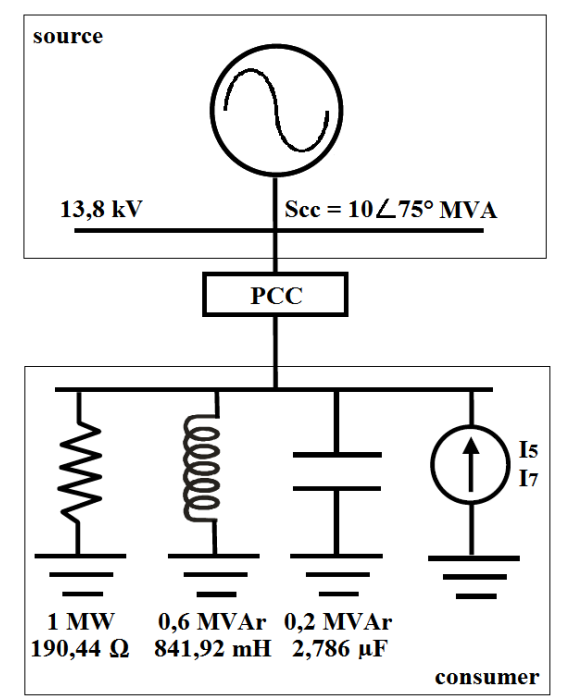

Fig. 5. System's electrical parameters.

The analyzed cases are shown in Table I and consider the responsible for the harmonic distortions and also the individual voltage and current distortion values for each case.

TABLE I

Evaluated CASES

\begin{tabular}{cccccc} 
CASE & RESPONSIBLE & $\mathbf{I}_{5}[\mathbf{A}]$ & $\mathbf{I}_{7}[\mathbf{A}]$ & $\mathbf{V}_{\mathbf{5}} \%$ & $\mathbf{V}_{\mathbf{7}} \boldsymbol{\%}$ \\
\hline $\mathbf{1}$ & - & - & - & - & - \\
\hline $\mathbf{2}$ & Consumer & 4 & 2 & - & - \\
\hline $\mathbf{3}$ & Consumer & 6 & 4 & - & - \\
\hline $\mathbf{4}$ & Supplier & - & - & $4 \%$ & $3 \%$ \\
\hline $\mathbf{5}$ & Supplier & - & - & $8 \%$ & $6 \%$
\end{tabular}

The results from the computational simulations are shown on Tables II and III. They present the measured values at the PCC.

Table II presents the Fundamental Voltage values $\left(V_{1}\right)$, the RMS Voltage $\left(V_{r m s}\right)$, the Total Harmonic Distortion of Voltage $(T H D V)$, the Fundamental Current $\left(I_{1}\right)$, the RMS Current $\left(I_{r m s}\right)$ and the Total Harmonic Distortion of Current (THDI).

TABLE II

Voltage, CurRent AND Total Distortion

\begin{tabular}{ccccccc}
$\mathbf{C A S E}$ & $\mathbf{V}_{\mathbf{1}}[\mathbf{k V}]$ & $\boldsymbol{V}_{\boldsymbol{r m s}}[\mathbf{k V}]$ & $\mathbf{T H D V} \%$ & $\mathbf{I}_{\mathbf{1}}[\mathbf{A}]$ & $\boldsymbol{I}_{\boldsymbol{r m s}}[\mathbf{A}]$ & $\mathbf{T H D I \%}$ \\
\hline $\mathbf{1}$ & 13,8 & 13,8 & $0 \%$ & 45,06 & 45,06 & $0 \%$ \\
\hline $\mathbf{2}$ & 13,8 & 13,838 & $7,39 \%$ & 45,06 & 45,43 & $12,86 \%$ \\
\hline $\mathbf{3}$ & 13,8 & 13,909 & $12,57 \%$ & 45,06 & 46,04 & $20,93 \%$ \\
\hline $\mathbf{4}$ & 13,8 & 13,817 & $5 \%$ & 45,06 & 45,16 & $6,76 \%$ \\
\hline $\mathbf{5}$ & 13,8 & 13,869 & $10 \%$ & 45,06 & 45,47 & $13,51 \%$
\end{tabular}

Case 1 shows no harmonic distortion. Cases 2 and 4 show a THDV below 10\%. Cases 3 and 5 exceed this value. 
Table III shows the values for Fundamental Power Factor $\left(F P_{1}\right)$; Power Factor $(F P)$; Fundamental Active Power $\left(P_{1}\right)$; and Total Active Power $(P)$, representing the instantaneous power's average value given by $(7)$ and for Active Power Absorbed by the Consumer $\left(P_{C}\right)$, calculated in (12).

TABLE III

Power FACTOR AND ACTIVE POWER

\begin{tabular}{cccccc}
$\mathbf{C A S E}$ & $\boldsymbol{F P}_{\mathbf{1}}$ & $\boldsymbol{F P}$ & $\boldsymbol{P}_{\mathbf{1}}[\mathbf{k W}]$ & $\mathbf{P}[\mathbf{k W}]$ & $\boldsymbol{P}_{\boldsymbol{C}}[\mathbf{k W}]$ \\
\hline $\mathbf{1}$ & 0,928 & 0,928 & 1000 & 1000 & 1000 \\
\hline $\mathbf{2}$ & 0,928 & 0,918 & 1000 & 999,502 & 1005,466 \\
\hline $\mathbf{3}$ & 0,928 & 0,901 & 1000 & 998,684 & 1015,8 \\
\hline $\mathbf{4}$ & 0,928 & 0,928 & 1000 & 1002,5 & 1002,5 \\
\hline $\mathbf{5}$ & 0,928 & 0,925 & 1000 & 1010 & 1010
\end{tabular}

For a more detailed comparison, the percentage difference between the active powers presented must be calculated. The Total Active Power $(P)$, calculated by the average of the instantaneous power's waveform and used in the searched literature on distorted signs, was adopted as reference.

Thus, the percentage difference between the Fundamental Active Power $\left(P_{1}\right)$ and the Total Active Power $(P)$ is given:

$$
\Delta P_{1} \%=\left[\left(\frac{P_{1}}{P}\right)-1\right] \times 100 \%
$$

And the percentage difference between the Active Power Absorbed by the Consumer $\left(P_{C}\right)$ and the Total Active Power $(P)$ is:

$$
\Delta P_{2} \%=\left[\left(\frac{P_{c}}{P}\right)-1\right] \times 100 \%
$$

Table IV presents $\Delta P_{1} \%$ and $\Delta P_{2} \%$ values.

TABLE IV

Percentage DifFerence Between the Active Powers

\begin{tabular}{cccc}
$\mathbf{C A S E}$ & $\mathbf{P}[\mathbf{k W}]$ & $\Delta \boldsymbol{P}_{\mathbf{1}} \%$ & $\Delta \boldsymbol{P}_{\mathbf{2}} \%$ \\
\hline $\mathbf{1}$ & 1000 & $0 \%$ & $0 \%$ \\
\hline $\mathbf{2}$ & 999,502 & $+0,05 \%$ & $+0,597 \%$ \\
\hline $\mathbf{3}$ & 998,684 & $+0,132 \%$ & $+1,714 \%$ \\
\hline $\mathbf{4}$ & 1002,5 & $-0,25 \%$ & $0 \%$ \\
\hline $\mathbf{5}$ & 1010 & $-1 \%$ & $0 \%$
\end{tabular}

According to the data presented in Table IV, for Case 1, in which the electric utility provides a purely sinusoidal voltage only for the consumer's linear loads, the values of Fundamental Active Power $\left(P_{1}\right)$, of Total Active Power $(P)$ and of Active Power Absorbed by the Consumer $\left(P_{C}\right)$ are the same, as expected.

In Cases 2 and 3, in which the electric utility provides a purely sinusoidal voltage to the consumer's linear and nonlinear loads, the value of the Total Active Power $(P)$ is lower than the Fundamental Active Power $\left(P_{1}\right)$. However, the Active Power Absorbed by the Consumer $\left(P_{C}\right)$ has a higher value when compared to the Fundamental Active Power $\left(P_{1}\right)$ value.
In Cases 4 and 5 , in which the electric utility provides a distorted voltage only for the consumer's linear loads, the values of Total Active Power $(P)$ and Active Power Absorbed by the Consumer $\left(P_{C}\right)$ are identical and both higher than the Fundamental Active Power $\left(P_{1}\right)$.

\section{Computational Assessment}

The electric energy billing in nonsinusoidal conditions is a controversial issue. Due to the measurement errors in meters, to the lack of standards and limits for harmonic distortion, the relationship between electric utility and consumer can be affected.

Through computational simulations of various cases and harmonic distortion conditions, this paper has presented a comparison of three values of active power: the Fundamental Active Power $\left(P_{1}\right)$, the Total Active Power $(P)$ and the Active Power Absorbed by consumer $\left(P_{C}\right)$.

When the utility is responsible for the harmonic distortions at the PCC, as in Cases 4 and 5, the Fundamental Active Power $\left(P_{1}\right)$ billing is the fairest. This is due the fact that the Total Active Power $(P)$ has a higher value, due to the increase in Active Harmonic Power $\left(P_{H}\right)$, unwanted portion by the consumer and responsibility of the supplier.

For Cases 2 and 3, in which the consumer is responsible for the harmonic distortions at the PCC, the electric energy billing becomes more complex. The Active Harmonic Power $\left(P_{H}{ }^{\prime \prime}\right)$ flow has an opposite direction compared to the direction of the Fundamental Active Power $\left(P_{1}\right)$, thus, the value of the Total Active Power $(P)$ will have its value decremented. The Active Power Absorbed by the Consumer $\left(P_{c}\right)$ could be used for the energy billing, however, a portion of it is coming from the harmonic distortion caused by the consumer, that is, the consumer absorbs part of the Active Harmonic Power $\left(P_{H}\right)$ from its own nonlinear loads. In these cases, the measurement of Total Active Power $(P)$ for electric energy billing harms the electric utility, since, besides being responsible for harmonic distortions, the consumer have its billing reduced.

The Total Active Power's $(P)$ value is highly influenced by the harmonic distortion at the PCC. Therefore, the measurement of Fundamental Active Power $\left(P_{1}\right)$, for electric energy billing, is shown as the best alternative in nonsinusoidal conditions as because it prevents further damage to the relationship between utility and consumer.

The results and analysis obtained with this study do not take account to the operational situation in which both the electric utility and the consumer are responsible for voltage distortions at the PCC. This is a complex situation and involves the sharing of responsibilities on the harmonic content, controversial topic and still under study. 


\section{Acknowledgement}

The authors express their thanks to CAPES, FAPEMIG and $\mathrm{CNPq}$ for the financial support and to Federal University of Uberlandia and PUC-GO for supplying all the structure to the accomplishment of this work.

\section{References}

[1] M. E. Balci, M. H, Hocaoglu, "Comparison of Power Definitions for Reactive Power Compensation in Nonsinusoidal Conditions", 11th International Conference on Harmonics and Quality of Power, p. 519-524, 2004.

[2] C. Budeanu, "Puissances Réactives et Fictives", Institut National Roumain, Bucarest, 1927.

[3] S. Fryze, "Wirk-, Blind-, und Scheinleistung in Elektrischen Stromkreisen Mit Nichtsinusoidalformingen Verfauf von Strom und Spannung", Elektrotechnische Zeitschriji, v. 53, n. 25, p. 596-599, 1932.

[4] M. Depenbrock, "Wirk- und Blindleistung", ETGFachtagung Blindleistung, Aachen, 1979.

[5] L. Czarnecki, "Considerations on the Reactive Power in Nonsinusoidal Situations", IEEE Transactions on Instrumentation and Measurement, v. 34, n. 3, p. 399-405, 1985.

[6] IEEE Standard Definitions for the Measurement of Electric Power Quantities Under Sinusoidal, Nonsinusoidal, Balanced, or Unbalanced Conditions, IEEE Standard 14592000, 2000.

[7] IEEE Standard Definitions for the Measurement of Electric Power Quantities Under Sinusoidal, Nonsinusoidal, Balanced, or Unbalanced Conditions, IEEE Standard 14592010, 2010.

[8] A. A. Girgis, T. L Baldwin, E. B Makram, H. R Fortson, "Testing the Performance of Three-phase Induction Watthour Meters in the Presence of Harmonic Distortion," IEEE Transactions On Industry Applications, v. 26, n. 4, p. 689 - 695, 1990.

[9] T. Tirano, H. Wada, "Effect of Waveform Distortion on Characteristics of Watt-hour Induction Meter", Electrical Engineering in Japan, v. 89, n. 4, p. 29-39, 1969.

[10] L. R. Lisita, G. B. Santos, P. C. M. Machado, D. Pinheiro Neto, e J. V. M. de Oliveira, "Avaliação de desempenho de medidor monofásico de energia elétrica do tipo indução operando com cargas residenciais", VIII Conferência Brasileira sobre Qualidade da Energia Elétrica, 2009.

[11] Y. Baghzouz, O. T. Tan, "Harmonic analysis of induction watthour meters performance", IEEE Transactions on Power Apparatus and Systems, Baton Rouge, v. PAS-104, n. 2, p. 399-406, 1985.

[12] C. J. Chou, C. C. Liu, "Analysis of the performance of induction watthour meters in the presence of harmonics", IEEE Electric Power System Research, New York, v. 32, p. 71-79, 1995.

[13] L. S. Silva, "Influência das distorções harmônicas em medições de energia elétrica", Dissertação de Mestrado, Faculdade de Tecnologia, Universidade de Brasília, Brasília, DF, 2006.

[14] E. Moulin, "Measuring Reactive Power in Energy Meters", Metering International, issue 1, p. 54, 2002.

[15] SSEP, "Simulador de Sistemas Elétricos de Potência Manual do Usuário”, Versão V2, QUALITY Engenharia e Sistemas Ltda., Disponível em: www.qes.com.br. 